\title{
Promotion of Internet Technology to Cross-border Cultural Communication Analysis
}

\author{
Tingting Xiao \\ Foreign Languages Department \\ Jilin Institute of Chemical Technology \\ Jilin, China 132022
}

\begin{abstract}
The intervening of network media for international cultural transmission has changed the current structure of cultural transmission and brought the transnational cultural communication into the digital age. In view of the long history of cultural communication between China and South Korea, network media provides a new opportunity for China and South Korea's cultural communication with its strong technical advantages, Under the historical background that in years of 2016 is the 24th Anniversary of the establishment of China-South Korea diplomatic Relations as well as the year of Sino-Korea exchange, according to the unique differences between Chinese and Korean people in the network cultural communication, taking the cultural communication between China and Korea as the research object, from the perspective of network transmission, the paper carries on the rational thinking and analysis to China and South Korea's cultural communication in network media environment, and discusses the influence and effect of network transmission on cross-cultural communication. The study points out that democracy and freedom in cyberspace make cultural communication in cyberspace more creative, cultural communication need more interaction in the network media environment. In addition, cultural communication between China and South Korea need to seek common ground while reserving differences, and try to find common ground. Between different cultures actively engage in exchanges and dialogue, mutual communication, learn from other culture's positive factors, mutual complementarity, mutual blending, so as to achieve diversified exchange development.
\end{abstract}

Keywords-internet; information technology; cross-border cultural communication; Chinese and Korean culture; cultural consumption

\section{INTRODUCTION}

Since the late 80 s and early 90 s of the 20th century Internet technology began to provide services to civil, to the beginning of the 21 st century, after just a dozen years' time (Rocha, 2012), it had been amazing popularity, it is changing people's living habits in all directions, and gave birth to the network economy and the new form of the development of cultural industry, made the boundaries between the Internet industry and cultural industry increasingly blurred (Antunes, 2004). In an increasingly flat world, the Internet has fundamentally changed the interactive relationship between "transmission" and "audience", and profoundly changed the way of cultural production, promotion and consumption (Chen \& Ractham, 2013). At the same time, the rise of the network also makes cross-cultural communication with the new characteristics compared with the pass, that is crosscultural communication carry out simultaneously and interactively in the cyberspace and real space, this new feature on the one hand to promotes people's understanding and communication between different cultures, on the other hand also exacerbates the people's misunderstanding and estrangement between different cultures (Lim,Yap and lan, 2010, Leite et al., 2016).

In the past, cross-cultural communication has been studied from a single perspective, that is, place cross-cultural communication in the cyberspace or the real space for single perspective research, such researches often exist limitations (Cowley\& Hanna, 2005). If the authenticity and accuracy of the information can't be guaranteed, it will lead to misunderstanding and estrangement, conflict and confrontation among different cultural backgrounds in cyberspace (Hanna et al., 2007). It will impede the smooth intercultural communication in cyberspace. While at the same time it will bring negative impact on cross-cultural communication in real space (Holtrugge et al., 2012; Lucas and Souza, 2016)

Regarding to the above-mentioned problems, the paper investigates cross-cultural communication from the perspective of interaction between cyberspace and real space (Starke-Meyerring, 2004). In this paper, we take the crosscultural communication between China and Korea as the breakthrough point, select Qingdao Chengyang Koreans gathering area as the field survey points, select the network forums established by China and South Korea as the network survey points (Yoon, 2011), through the combined method of observation, interview and questionnaires to collecting data, and the operating mode of the cross-cultural communication in the interaction between the cyberspace and the real space is investigated (Lewis \& George,2008). The reasons for smooth proceed of the cross-cultural communication in the interaction between the network and the real space is explored. The purpose of this study is to provide useful information for the friendly exchanges between people of different cultural backgrounds in the new era. 


\section{INTERCULTURAL COMMUNICATION IN CYBERSPACE}

The Internet has created a new interactive space for contact and cross-cultural communication to people from different countries, cultures and nations (Jiang and Wen, 2009). Unlike the form of cross-cultural communication in the real space, intercultural communication in cyberspace is carried out in its unique form and characteristics (Bruce, 1979). In the real space, there is little contact between Chinese and Korean people and cultural communication. On the contrary, in cyberspace, the people of China and South Korea frequently explore each other.

\section{A. Communication in Cyberspace}

Because Chengyang is concentrated area where the Korean people live in, Chengyang Sino-Korea Cultural communication Network Forum naturally becomes a cyberspace for searching and cultural exchanging between the Chinese and the South Korean people (Roger and Cheryl, 2008). For a period time of observation and analysis on the forum post found that there were a total of 255 posts be searched out by using "South Korea" as a keyword in the site during the past six months, if computing in day, then a new post which using "South Korea" as a keyword will appears an average day. The posts using "south Korea" as a keyword will appear an average day. The posts using "South Korea"as the keyword are divided into several categories, one kind of Chinese and Korean culture posts, this posts is generally introduce customs, cultural difference between China and south Korea; the rest is China and South Korea evaluation of Koreans in Chengyang. In these posts, the discussion of evaluation posts of China and South Korea is particularly intense. For example, in November 29, 2015 Chengyang user "Youxian" published a post "talk about my impressions of ChengYang Koreans", in ChengYang gossip section of the ChengYang forum, this post has triggered an extensive discussion of Chengyang Users, until December1, 2015, and the post had a total 1 of 192 "reply."

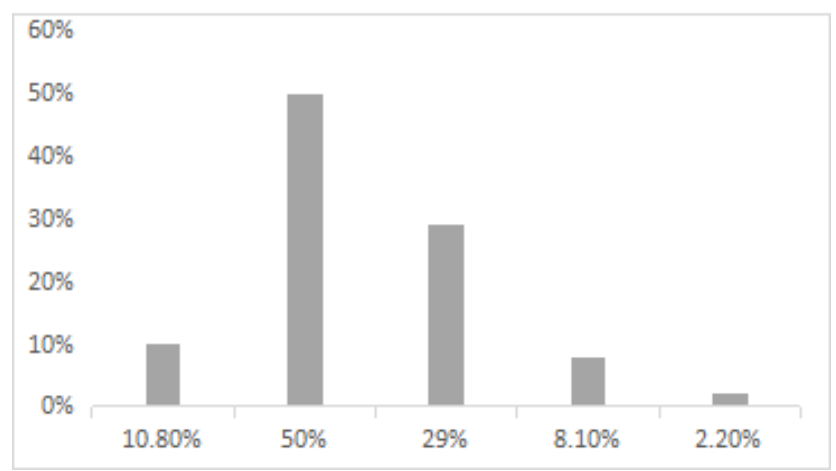

Fig. 1. Koreans'attention to evaluation of Chinese to Koreans on Internet.

A questionnaire survey of Koreans in Qingdao shows that most Koreans are more concerned with the evaluation of Chinese to Koreans on Internet, and only a small percentage of them do not care in 'Fig. 1"(Ying and Sun,2009). Among them, $10.8 \%$ of the Koreans expressed great concern about the evaluation of Chinese to Korean,50\% of South Koreans expressed concern, $29 \%$ of South Koreans expressed general concern, while $8.1 \%$ did not pay attention, expressed very little attention is only $2.2 \%$. From evaluation and discussion of Chinese to Koreans in networks,as well as the higher degree of concern from Korean people on evaluation of Chinese to Koreans, it can be seen that they are frequently explore each other between the Chinese and South Korean people in cyberspace (Mehra and Papajohn,2007).In the view of main content of the entire website, Chinese news is the most in the various types of information, all this information provide a window for the Koreans in Qingdao to understand China (Xiang,2008).

Based on the above observations of content of two Chengyang website forum of China and South Korea, netizens from China and South Korea are mainly in browsing information, releasing information, replying to the information and other ways to familiar with each other, understanding, contacting and cultural communication in the network.

\section{B. The Media Effect of Cultural Information}

Compared with the real space, the Chinese and Korean people are more likely to explore each other in cyberspace (Gerber, 2012).The main reason is that the intermediary and carrier of this explore is information, people with different cultural backgrounds can search for the information resources according to their own situation and needs, so as to achieve each other's understanding, awareness, contact and cultural communication. Chinese and Korean people to interact with each other through information obtained on Internet (Skoric and Park, 2014). In essence, the interaction is a kind of indirect, people-information-people of non-face interaction process.

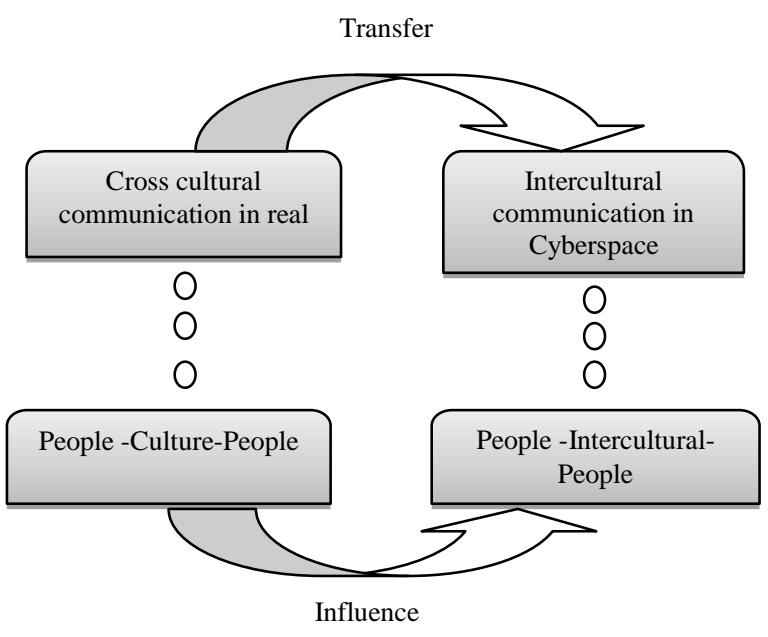

Fig. 2. Cultural communication model.

When people open the computer, click the mouse to enter the cyberspace constructed by Internet, people began a way of interaction different with that of the real space, we are not directly facing a single person or group, but the computer screen and the text, pictures, sound, video and other information presented by computer screen(Rivera \& Rogers,2006).The essence of people's contact and communication between different cultural backgrounds in cyberspace is the people-information-people interaction 
process in "Fig. 2".In the intercultural communication of cyberspace, the information elements have replaced the cultural elements which play an important role in communication in the real space, all of these make the information become the most important intermediary for the interaction between people (Docenko, 2012).

\section{CROSS-CULTURAL COMMUNICATION OF NETWORK AND REAL WORLD}

\section{A. The Impact of the Network}

The Internet connects people from different countries, nations and cultures, and provides convenient conditions and communication opportunities for people from different culture backgrounds(Gates,2013).Intercultural communication in cyberspace has profound impact on cultural communication in the real world, the impact includes both positive and negative impact. Intercultural communication in cyberspace promotes cross-cultural communication in real space and enhances communication between different cultural groups in both countries, this is the positive aspect(Jang and Barnett,1994). While Intercultural communication in cyberspace is not smooth, in the real world cross-cultural communication will also be affected to varying degree, resulting in the gap between different cultural groups, intercultural communication can't be sustaining and normally proceed, this is the negative aspect (Petr \& Gauzente, 2013).

Since 2005, beginning with Korean's inscription success of "Dragon Boat Festival" the "Sino-Korean cultural dispute" started in network (Verjans et al., 2015). Then many socalled South Korean professors claimed that "poet Li Bai is a Korean". SunZhongshan is a Korean", "Korean national invented the Chinese characters" and soon the information of Chinese culture source from South Korea is full of forums and websites. Before and after the 2008 Beijing Olympic Games, such as "torch relay storm", "Wenchuan Earthquake evil" "Olympic opening ceremony leak", these events which are not conducive to the friendly relations between China and South Korea had also widely spread through the network(Wu, 2012). In addition, some people who have been to Korea or have contact with Koreans through the blog. The site forum breaks down the information that all sorts of unfriendly words and deeds of Koreans to China and Chinese, that information also were widely reproduced by users on network. The emotions of "Dislike Korea Hate Korean and even Anti-Korean" in the network have continued to heat up and start to extend from the network to the real world, which has affected the Sino-Korean folk relations and even international relations.

In response to the intensified emotions of "Dislike Korea", "Hate Korean" and "Anti-Korean" in cyberspace, On September 5th, 2008, South Korean civil organization officially announced that they would launch a campaign in China called "Modesty and Warmth activities". And specially the establishment of the"modest and warmth activities headquarters", to promote to carry out the development of a variety of colorful activities by the committee, such as actively excavate positive examples $\mathrm{u} /$ promote the friendly relations between the two countries (Jean et al., 2010) to help the unfortunate people around, to carry out scholarship matters on the whole had made certain achievements in the promotion of Korean folk relations.

According to the results of 7192 questionnaires, 71.7 percent of Koreans said they had heard of the "Hate Korea" of public opinion in the network in "Fig. 3". 9\% of Koreans who have ever heard the emotion of "Dislike Korea" and "Hate Korea" thought emotion of " Dislike Korea" and "Hate Korea" was very serious, $38.2 \%$ of people think that this emotion is serious and fuss. $48.7 \%$ of people think that such emotion is not serious (Popova, 2013), there are 5.3\% of people think that no need to make a fuss.

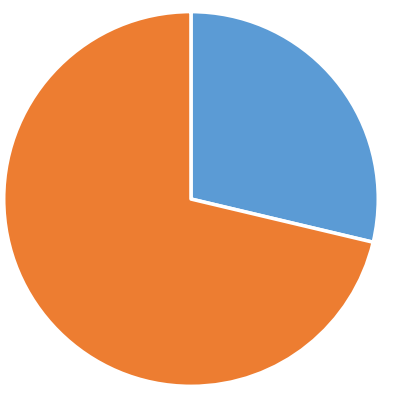

Never heard of it $\square$ Heard of it

Fig. 3. Ever heard of the " Dislike Korea"and "Hate Korea" of public opinion.

Regarding to the disseminated emotion of "Dislike Korea" and "Hate Korea", a large proportion of Koreans lived in Qingdao believed it had affected their daily life to a certain extent, account for $28 \%$ of total respondents, who thought the influence is very large of total responds account for $4.8 \%$, who taught the influence is large account for $21.4 \%$, very small accounted for $18.5 \%$, only a small number of people thought it had no influence or with the attitude of uncertain. However, many of the information disseminated on the network has been proven to be false.

\section{B. The Power of Information}

At Internet age, the role of power of culture in the crosscultural communication is reducing, while the power of information plays a more and more important role in crosscultural communication. Information has become an important intermediary in the process of cross-cultural communication at Internet age, and demonstrates its great strength, which controls the smooth progress of crosscultural communication.

The fast accessed information of the network brings people infinite convenience, also makes the intercultural communication benefit from it. People of different cultural backgrounds can know each other instantaneously through the information on the network, and can communicate with the objects that want to communicate through fast information. When the information is rapid spreading and 
affecting the cross-cultural communication, another attribute of information becomes very important, it is the accuracy and authenticity of information. This attribute directly affects the success of cross-cultural communication. Today with the highly development of Internet, countless of the information generated every day, for cross-cultural communication which require to use information intermediary to complete in cyberspace, the accuracy of information is particularly important. If the information is accurate and truth, it can promote the cross-cultural communication to proceed smoothly in cyberspace, otherwise it will hinder the process of cross-cultural communication, the accuracy of information control "quality" in cross-cultural communication.

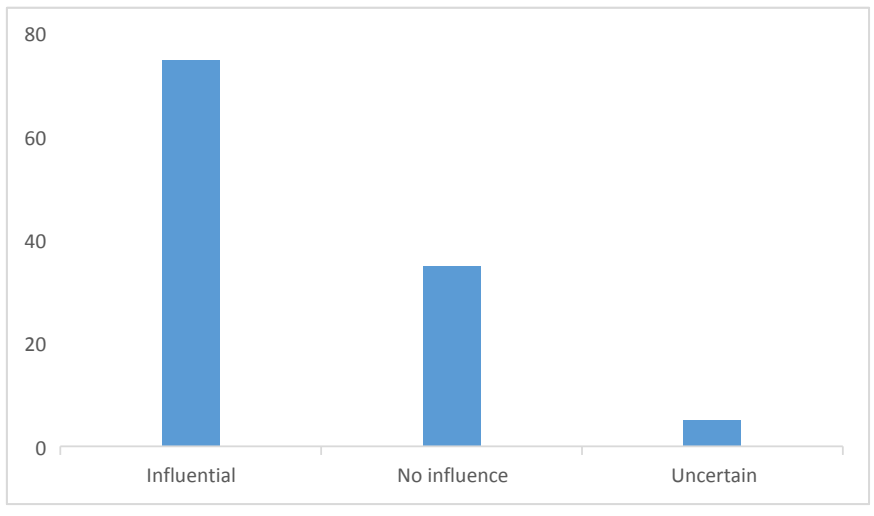

Fig. 4. Influence of "Dislike Korea",'Hate Korea” on the Korean Daily Life in Qingdao of Public Opinion

The "fast" and "accurate" of information relates with the "quantity" and "quality" of cross-cultural communication. The choice of "fast" and "accurate" of information, in fact is the choice of "quantity" and "quality" of cross-cultural communication. If the information only showing its "fast" attribute, then cross-cultural communication may be only has the growth in "quantity", and can't bring improvement on the "quality" of cross-cultural communication. "Quality" improvement of cross-cultural communication is guaranteed by "accurate" attribute of the information, and this guarantee is the result of the interaction of the "publisher" and "recipient" of the information.

Our ultimate desire is to increase cross-cultural communication "quantity" while cross-cultural communication "quality" is also guaranteed. But the fact is often not the case. With the aid of information, Crosscultural communication in cyberspace generally takes place in three steps: the generation of information, the reception of information, and the action of information, the publisher and recipient of information are responsible to the first two steps, cross-cultural communication is the result of the last step. When the information is manipulated by people with various purposes and lost its original authenticity and accuracy, at the same time the inaccurate information are selectively received by the people has been lost the ability to distinguish, thinking, then the effect of information as important intermediaries will be hindered in cross-cultural communication.

\section{CONCLUSION}

Network media has become the new fulcrum of cultural communication. The Internet achieved instantaneous spread of information within the wide area, made the different cultural patterns unprecedented approaching, and realized free exchange of a variety of different ideas. All these have greatly promoted the cultural development of different nations and regions, and also led to the generation of new cultural forms. The democracy and freedom of cyberspace make the cultural communication more creative, laying a technical foundation for the development of culture.

Cultural communication need to interact in the network media environment, Cultural communication, not only to come in, but also to go out, the freedom and opening of Internet has opened up a door for cultural communication between China and South Korea, give both China and South Korea an equal opportunities, and only make good use of this opportunity and let two cultures learn from each other, can achieve considerable development in cultural communication and collisions.

Cultural communication between China and South Korea need to seek common ground while reserving differences. In terms of culture, we advocate seek common ground while reserving differences, that is, under the conditions of recognizing the differences and diversity strive to find common ground, actively engage in exchange and dialogue between the different cultures, mutual communication, learn from other culture's positive factors, mutual complementarity, mutual blending, so as to achieve mutual development.

\section{REFERENCES}

[1] Antunes, A.A. (2004). Sistemas XYZ. In Sousa A.J. (Ed.), Tecnologias Internet. Lisboa: Editora Xxxpto.

[2] Bruce, W.S. (1979). Problems in cross-cultural contact: a literature review. International Journal of Intercultural Relations, 3(3), 269-313.

[3] Burima, M. (2015). Cemeteries in latvia and belarus as the object of area studies in the context of cross-border culture communication.

[4] Chen, C.C., \& Ractham, P. (2013). Adopting internet telephony technology as a cross-cultural communication training tool. Lecture Notes in Control \& Information Sciences, 30(9), 781-781.

[5] Cowley, P., \&Hanna, B.E.(2005). cross-cultural skills-crossing the disciplinary divide. Language\& Communication, 25(1), 1-17

[6] Djurdjevic, M,\& Girona, J. R(2016). Mixed couples and critical cosmopolitanism experiences of cross-border love. Journal of Intercultural Studies, 37(4), 390-405.

[7] Docenko, T.(2012). Associative-verbal network in the context of cross-culture communication. Philological Studies (10), 155-165.

[8] Gates, K.(2013). Key questions for communication and criticalcultural studies posthumanism, network infrastructures, and sustainability. Communication and Critical/Cultural Studies, 10(2-3), 242-247.

[9] Gerber,M.M.(2012). The plausibility of cross-national comparisons of internet use types. Information Society, 28(2), 83-98

[10] Hanna,Nooy,B.E.,\& De, J(2007). Negotiating cross-cultural difference in electronic discussion. Multilingua, 23(3), 257-281.

[11] Holtbrugge, D., Weldon,A.,\&Rogers, H.(2012). Cultural determinants of email communication styles. International Journal of Cross Cultural Management, 13(1),89-110. 
[12] Jang, H.Y.,\&Barnett,G.A.(1994). Cultural differences in organizational communication a semantic network analysis 1 . Bulletin De Methodologie Sociologique Bms, 44(1)971-952

[13] Jean, RJ., Sinkovics, R.R., \& Kim, D(2010). Drivers and performance outcomes of relationship learning for suppliers in cross-border customer-supplier relationships the role of communication culture. Journal of International Marketing, 18(1), 63-85.

[14] JIANG,\& Wen-hui. (2009). Image of guilin: mine, yours and his or hers on cross-cultural awareness of a city destination in tourism. UsChina Foreign Language,28(10),7-17

[15] Leite, P., Goncalves, J., Teixeira,P.,\& Rocha, Ã.(2016). A model for the evaluation of data quality in health unit websites. Health Informatics Journal, 22(3), 479-495

[16] Lewis, C.C., \&George, J.F.(2008). Cross-cultural deception in social networking sites and face-to-face communication. Computers in Human Behavior, 24(6), 2945-2964

[17] Lim, Y.M., Yap, C.S., \& Lau, T.C. (2010). Response to internet advertising among malaysian young consumers. Cross-Cultural Communication, 6(2),93-99

[18] Lucas J.R.D., Souza C.A.D. (2016). Mudancas no Marketing das Organizaçòes Decorrentes do Uso de Plataformas de Redes Sociais: Casos Brasileiros RISTI-Revista Ibérica de Sistemas e Tecnologias de Informaça o, n18, 83-98. Dot10.17013/risti.18.83-98

[19] Mehra, B, Papajohn, D. (2007). "glocal" patterns of communicationinformation convergences in internet use: cross. International Information\& Library Review, 39(1),12-30.

[20] Papajohn,B.M.D.(2013). "glocn1" patterns of communicationinformation convergences in internet use: cross-cultural behavior of international teaching assistants in a culturally alien information environment. International Information \& Library Review,39(1),1230.1

[21] Petr , C., \& Gauzente, C. (2013). The use of social network sites as catalyst for more communication and affiliation regarding to cultural organization. Revista Espafiola De Salud Puiblica, 77(2),245-255.

[22] Popova, J. ( 2013 ). Attitudes and prerequisites for the establishment of an integrated cultural identity within romanian-bulgarian crossborder region along the danube river. Journal of Danubian Studies \& Research,3(1)

[23] Rivera, M.A., \&Rogers, E.M. ( 2006 ) . Innovation diffusion , network features, and cultural communication variables . Problem \& Perspectives in Management , 4 ( 2 )

[24] Rocha , Ã . ( 2012 ) Framework for a Global Quality Evaluation of a Website . Online Information Review , 36 ( 3 ), 374-382.

[25] Roger , V. Cheryl , R. ( 2008 ) . Negotiating on the internet: insights from a cross-cultural exercise . Journal of Education for Business, 83 ( 3 ) , 165-172.

[26] Skoric, M.M., \& Park , Y.J. ( 2014 ) . Culture, technologies and democracy: a cross-national analysis of political development . Telematics \& Informatics, 31 ( 3 ), 364-375.

[27] Starke-Meyerring, D. (2004). The rhetoric of the internet in higher education policy: across-cultural study. Business Communication Quarterly, 67(2), 238-244.

[28] Verjans, M., Swinnen, G., Huysmans, M., \& Caers, E. (2015). Crosscultural research in cross-border regions: verbal and non-verbal professional communication method and survey design.

[29] Wang, Y., Sun, S.J. (2009). Examining Chinese students' internet use and cross-cultural adaptation: does loneliness speak much? Asian Journal of Communication, 19(1), 80-96.

[30] Wu,Y. (2012). Cross-cultural communication in cross-border m\&a of enterprises. Cross-Cultural Management.

[31] Xiang, Z. (2008). Cultural dimensions and framing the internet in China a cross-cultural study of newspapers' coverage in Hong Kong, Singapore, the US and the UK. International Communication Gazette, 7o (2), 117-136.

[32] Yoon, KJ. (2011). Understanding cultural values to improve crosscultural communication: an ethnopragmatic perspective to Korean child rearing practices. Mlsk. or. kr, 26(4),879-899. 